\title{
Que inovação pedagógica a pedagogia queer propõe ao currículo escolar?
}

\author{
Alfrancio Ferreira Dias* \\ Carlos André Araújo Menezes**
}

\section{Resumo}

O propósito desse texto é problematizar as potencialidades de uma pedagogia e um currículo queer na escola. Problematizamos o argumento de que a pedagogia queer propõe uma nova postura política, inserindo novas estratégias, atitudes, procedimentos pedagógicos subversivos, demancando possibilidades de negociação no espaço escolar. Conclui-se que, estranhar o currículo da escola, passar a seruma das inovações que a pedagogia queer propõe a a@s estudantes e professor@shoje.

Palavras-chave: Pedagogia Queer. Currículo Queer. InovaçãoPedagógica.

* Doutor em Sociologia. Professor do Departamento de Educação e do Programa de Pós-graduação em Educação da Universidade Federal de Sergipe. E-mail: diasalfrancio@gmail.com

** Professor de Língua Portuguesa e Língua Estrangeira na Educação Básica. Mestrando em Educação pelo Programa de Pós-graduação em Educação da Universidade Federal de Sergipe. E-mail:aramen2005@ hotmail.com 


\section{What pedagogical innovation does Queer Pedagogy propose to the school curriculum? \\ ¿Qué innovación la pedagogía queer propone al currículo de la escuela?}

\section{Abstract}

The purpose of this text is to problematize the potentialities of a queer pedagogy and curriculum in the school. We problematize the argument that queer pedagogy proposes a new political stance, inserting new strategies, attitudes, subversive pedagogical procedures, creating new possibilities of negotiation in the school space. It is concluded that, it's necessary to the curriculum of the school, to become innovations that queer pedagogy proposes to students and teachers nowdays.

Keywords: Queer Pedagogy. Queer Curriculum. Pedagogical Innovation.

\section{Resumen}

El propósito de este texto es problematizar las potencialidades de una pedagogía y un currículo queer en la escuela. Problematizamos el argumento de que la pedagogía queer propone una nueva postura política, injiriendo nuevas estrategias, actitudes, procedimientos pedagógicos subversivos, demandando posibilidades de negociación en el espacio de la escuela. Se concluye que, extrañar el currículo de la escuela, pasa a ser una de las innovaciones que la pedagogía queer propone a los estudiantes y a los profesores de hoy.

Palabras clave: Pedagogía Queer. Currículo Queer. Innovación pedagógica. 
Nas últimas duas décadas temos vivenciados diversas experiências e situações didáticas com estudantes de diversos níveis de ensino (infantil, fundamental, médio e superior) e, sobretudo, em diferentes instituições, desde daquelas cituadas em comunidades tradicionais (rurais e quilombolas), como também em cidades maiores. Estas experiências didático-pedagógicas nos construíram como professores e hoje elas também estão nos descontruindo cotidianamente, fato que não sabemos que professores seremos amanhã.

A experiência de "ser professor" ou "estar sendo professor" nos permite olhar para nós mesmos, refletir a partir de cada contato com o outro, com as diversas narrativas e histórias de vida de estudantes e demais agentes escolares, com suas identificações e subjetividades. Ao retomarmos algumas lembranças, percebemos que todos esses aspectos foram importantes para nos mudar, tocar, despertar, agir, como bem nos argumenta Larrosa (2002, p. 21): a experiência é "o que nos passa, o que nos acontece, o que nos toca. A cada dia se passam muitas coisas, porém, ao mesmo tempo, quase nada nos acontece". A experiência docente nos permitiu também, refletir sobre como o ato pedagógico pode ser ato dialógico, no qual o conhecimento passa a ser produzido na relação, no cotidiano, na mediação e, sobretudo, na importância que damos aos papéis desempenhados tod@s ${ }^{3} @ s$ agentes escolares(alun@s, professor@s, pais e gestor@s).

Partimos da premissa de que o processo de aprendizagem deve ultrapassar as salas de aulas, os corredores, a biblioteca, o pátio e os tantos outros espçaos da escola. Ele deve(ria) ultrapassar os muros, derrumar barreiras e chegar onde@s alun@s estão, nos lugares de socialização, onde se vive e se pode aprender, ou seja, um "currículo-como-vida" (SOUSA, 2012), no qual a relação de tempo e espaço influencia as relações e os processo de socialização, propondo flexeções acerca das identidades e subjetividades cada vez mais descentradas e conflituosas.

O currículo-como-vida, segundo Sousa (2012, p. 20), "olha para a escola com desconfiança, se ela não for capaz de enfrentar os verdadeiros problemas que a huma- nidade atravessa e não fizer algo para os debelar". Nessa perspectiva, como pensar uma escola no singular? Para que serve a escola de fato? Quem ela pretende formar? Porque ainda se investe numa escolarização generificada? Que corpos são aceitos nesta escola? Que expressões de gênero e sexualidade são permitidas? A partir de nossa experiência profisisonal, de modo geral, existe um investimento de algumas instituições de ensino na escolarização de um corpo generificado, disciplinado e invisível (DIAS, 2014; DIAS;CRUZ, 2015; LOURO, 2010).

$\mathrm{Na}$ qual, investe-se em tecnologias de normalização dos corpos nas práticas escolares, com visíveis estratégias de controle e disciplinamento.

É preciso desconfiar da escola de temos. A escola é viva, é atravessada pelo problemas cotidianos das pessoas, ela simplesmente acontece. Nesta perspectiva, esse projeto de subjetivação do sujeito generificado não é aceito passivamente por todos estudantes. Alguns corpos questionam e enfrentam as normas de gênero e tantas outras possibilidades de controle dos corpos nas praticas escolares, conforme exposto por Dias e Cardoso (2016). Faz-se necessário, pois, trazer a tona também, os discursos desses sujeitos que perturbam, borram, rasgam as normas pautada na heteronormatividade. Dar voz aos/ às que, por muito tempo, estiveram no anonimato ou excluíd@s das aprendizagens escolares. Propor uma pedagogia Queer.

Nos últimos anos, nos influenciamos por leituras pós-estruturalistas e pós-críticas que possibilitaram e estão possibilitando processos de descontrução, enquanto professores e pesquidores. Isso não é uma tarefa fácil, mas possível, tendo em vista que buscamos sempre possibilidades de desconstruções e desaprendizagens. Essas leituras pós-críticas ${ }^{4}$ nos ajudam a refletir sobre nosso olhar para o currículo da escola, este tem sido na perspectiva de um sujeito com um olhar "descontruído" e "influente" (GASTALDO, 2012).

Não nos interessa pensar o currículo a partir de um único lugar, perspectiva e/ou de uma possível neutralidade. Mas sim, o currículo que acontece nas salas de aula, nas vivências do dia a dia, como um ato político cultural (SIL- 
VA, 2013), onde as assimetrias ${ }^{5}$, androcentrismo $0^{6}$, sexis$\mathrm{mo}^{7}$, racismo $^{8}$ e o heterossexismo ${ }^{9}$ passem a ser desprivilegiados a partir da perspectiva da diferença. A escola, por se só, já é diversa. $\mathrm{O}$ que nos interessa é o que fazemos com a diferença.

A pedagogia feminista e a queer contribuem para refletirmos acerca da diversidade e a diferença da escola, na medida em que ambas buscam promover a "conscientização, o empoderamento e a organização coletiva para a transformação das relações de dominação de gênero e a libertação dos indivívuos e grupos daquilo que limita sua participação social, intelectual e política" (CARVALHO; ANDRADE; MENEZES, 2009, 37). Sua aplicabilidade expressará, necessariamente, o diálogo e crítica à cultura do poder, estimulando um olhar e análise para o currículo escolar, para as salas de aula e outros espaços de socialização de questionamento e de mudança.

Um dos principais questionamentos é entender a escola como um "lugar" de socialização, de construção e aprendizagens de valores fundamentais para a cidadania e convívio social. Conteúdos tais como diversidade cultural, direitos humanos, equidade de gênero, diversidade e identificação sexual, relações étnicas, indígenas, sustentabilidade ambiental, classe, diversidade religiosa, geração, dentre outros, precisam ganhar visibilidade e amplo debate na educação básica. É o que propõe a pedagogia quer. Pensar a aprendizagem pelas diferenças na escola, bem como uma "educação que não impusesse modelos preestabelecidos de ser, de se compreender e de classificar de uns aos outros" (MISKOLCl, 2013, p. 55).

Para a Pedagogia queer, a educação e o currículo precisariam deixar de produzir "normalização biopolítica para o Estado e passasse a ser veículo social de desconstrução de uma ordem histórica de desigualdades e injustiças (MISKOLCl, 2013, p. 55), ou seja, a compreensão de que a aprendizagem extrapola as salas de aula e os muros das escolas. Ela, contribui para problematizar o nosso dia a dia e as relações sociais, refletindo sobre os aspectos que tornam(ram) a escola um espaço destinado a reprodução de valores hegemônicos e heterossexistas, conforme argumento apresentado por Berenice Bento:
[...] é necessário sair desse espaço, ampliar nosso olhar para a própria forma como a sociedade produz as verdades sobre o que deve ser produzido, quais os comportamentos de gênero sancionados e por que outros são silenciados e invisibilizados, qual a sexualidade se articula construída como "normal" e como gênero e sexualidade se articulam na produção social. Essas questões não podem ser respondidas exclusivamente nos limites da escola. Há um projeto social, uma engenharia de produção de corpos normais, que extrapola os muros da escola, mas que encontrará nesse espaço um terreno fértil de disseminação (BENTO, 2011, p. 556).

A "engenharia de produção de corpos normais" exposta por Bento pode ser utilizada como argumentação prioritária para a desconstrução da "possível" neutralidade do currículo escolar, bem como por pressupostos ancorados em ideias androcentricas, racistas e heterossexistas. Tal constatação, leva a reafirmar o papel da educação e do currículo escolar no que diz respeito a produção de aprendizagens mais amplas, que impactem no exercício da cidadania, questionando as tecnologias de produção de corpos normais, aderentes ou enquadrados num"normal" que precisa ser questionado.

A abordagem da pedagogia queer é influenciada pelo surgimento e disseminação dos estudos queer ${ }^{10}$. Os estudos queer nos permitem e nos ajudam a refletir acerca da "ambiguidade, a multiplicidade e a fluidez das identidades sexuais e de gênero, mas além disso, também sugere novas formas de pensar a cultura, o conhecimento, o poder e a educação" (LOURO, 2015, p. 48-49). Mas, como pode-se articular essa perspectiva à educação? Que espaço ela terá no currículo escolar para a transgressão das práticas normalizadoras, disciplinadoras e binárias? Quais mudanças propõe a prática pedagógica e vivência escolar?

Segundo Silva (2013, p. 107), a abordagem queer se torna uma "atitude epistemológica que não se restringe à identidade e ao conhecimento sexuais, mas que se entende para o conhecimento e a identidade de modo geral". Uma ação que "significa questionar, problematizar, contestar todas as formas bem-comportandas de 
conhecimento e de identidade". Ser Queer é uma "crítica das práticas de normalização que ocorrem no estudo da sexualidade. [...] refere-se a um conjunto de saberes (ao invés de um corpus teórico sistematizado e terminado) e a uma disposição política" (TRUJILLO, 2015, p. 1536 nossa tradução $)^{11}$. Neste sentido, consideramos que a pedagogia queer propõe uma nova postura política para tod@s na escola, inserindo novas estratégias, atitudes, procedimentos pedagógicos e posturas subversivas no cotidiano escolar.

Queer deve ser entendido como um adjetivo e como um movimento, ação, como um verbo: queerizar a escola, salas de aula, conhecimento, metodologias (e movimentos sociais, espaço público, etc). Uma pedagogia queer, como afirmou Luhman (1998), deve ir além da incorporação de conteúdo queer nos currículos e preocupação com a busca de estratégias de ensino que tornem esse conteúdo mais acessível para estudantes; $\mathrm{E}$ eu escrevo isso enquanto penso que muitas vezes é inevitável mover-se entre a urgência da prática diária (mas como trazemos tudo isso para a sala de aula?) e a análise e reflexão. (TRUJILLO, 2015, p. 1537, nossa tradução). ${ }^{12}$

Ao identifica-se com os pressupostos queer, temos tencionado nossas ações cotidianas nas escolas, na busca de desenvolver um trabalho vivo, fluido e preocupado não só com conteúdos específicos para serem trabalhados, mas sim, com ações que intensifiquem os sentidos que atribuímos as aprendizagens e as relações. Refletir sobre o ato de aprender d@s alun@s, com e a partir d@s alun@s.

Propor desaprendizagens ao currículo, está intimamente, ligado ao processo de nos desviar de um trabalho pedagógico normalizado pelo Estado, como no Brasil é posto nas políticas educacionais, para trabalhar com temáticas consideradas "excêntricas", "desviantes" ou "inteleráveis". Talvez, esse seja, de fato, o caminho mais profícuo para a problematização de diversas questões apontadas em outras pesquisas (DIAS; CARVALHO; OLIVEIRA, 2016; DIAS; CRUZ, 2015; DIAS; AMORIM, 2015). De modo geral, essas pesquisas mostram que algumas escolas ainda desenvolvem normas regulatória do bio- poder ${ }^{13}$ e da governabilidade nos corpos d@s estudantes ed@s profissionais, como por exemplo: a) a proibição do uso do banheiro por travestis e pessoas transsexuais; b) produção de práticas educativas que educam meninos e meninas para a anulação do corpo; c) investimento no distanciamento entre este e a mente; d) desenvolve uma linguagem que padroniza masculinidades e feminilidades; e) nas situações diárias despreza as experiências e inter-relações de alun@s e professor@s.

Apesar dessas pesquisas e muitas outras apontarem o frágil ou tímido trabalho com a diferença nos currículos escolares, a inclusão da perspectiva queer na educação e no currículo propõe desaprendizagens na escola, visto que não se busca por certezas definitivas ou absolutas. A vivência escolar é muito mais que tramissão de conhecimento, está mais próximo da criação de uma nova condição de aprendizagem do conhecimento, na qual abrange um processo menos previsível e mais desequilibrado de se envolver no conhecimento (TRUJILLO, 2015).

Apesar dos resultados de nossas pesquisas apontarem para a (re)produção de corpos normais na escola, esse processo não é passivo. Existe resistência e enfrentamento, conforme apontado por Dias, et al., (2017). @s autores apontam, a partir de algumas cenas de pesquisa de campo, realizadas em diferentes tempos e espaços, que nas práticas formativas e nos espaços que elas acontecem, há diversos espaços de subversões às normas e enfrentamos ao controle dos corpos, bem como mostram que esses lugares são de disputas, que geralmente, nas nossas pesquisas não privilegiamos os discursos que subvertem (DIAS, et al., 2017). Partindo dessa pressima, acreditamos que é preciso divulgar essas experiências escolares que protagonizem uma pedagogia e um currículo queer.

As cenas que apresentamos neste texto, trazem em si, o propósito de contribuir para exemplificar as potencialidades da pedagogia queer traz para o currículo escolar. Elas fazem parte das notas de campo do segundo autor deste texto e fazem parte da pesquisa em andamento, intitulada "Rasgando uniformes e descosturando identidades de gênero no espaço escolar", desenvolvida no Programa de Pós-graduação em Educação da Universi- 
dade Federal de Sergipe. A investigação de caráter etnográfica, pretende analisar se a expressão corporal de estudantes gays e lésbicas no espaço escolar contribui para ampliação do debate sobre diversidade de gêneroe sexual na escola; refletir os caminhos percorridos e obstáculos encontrados no percurso da escolarização d@s estudantes gays e sua inserção nas práticas curriculares escolares; rerificar se há indícios de desestabilização às normas de gênero a partir da presença de estudantes gays e lésbicas na instituição; identificar se a existência de estudantes gays e lésbicas na educação básica tem provocado mudanças curriculares.

\section{Uma escola inovadora? Um currículo queer?}

Tomamos como espaço de problematização, o Colégio Estadual Dr. Antônio Garcia Filho ${ }^{14}$, uma escola do território Centro-sul do estado de Sergipe, no qual o segundo autor deste texto atuou como professor por quase duas décadas e presenciou diversas praticas educativas que protagonizavam cenas multiculturais, que mobiliza(va) toda a população local, que sempre aguarda(va) as diversas atividades culturas de uma escola que abria as suas portas para a comunidade.

Algumas dessas atividades incomuns em outras escolas - rainha junina gay, casamento caipira gay, rodas de candomblé, shows de transformismos, dentre outras passaram a promover sentimentos diversos nas pessoas, a partir da convivência com as diferenças. Esses registros que fazem parte do memorial da escola, d@s alun@s, d@s demais agentes escolares e da cidade. Contudo, como apesar de algumas escolas ainda desenvolverem práticas regulatórias, conforme destamos acima, o Gárcia Filho produz outros saberes? E que saberes são esses? Quais práticas pedagógicas estão presentes quando certas posturas foram e são adotadas em relação a inserção de alguns corpos subversivos nas suas atividades cotidianas?

Não temos a intensão de encontrar respostas ou novas verdades. Mas sim, problematizar e permitir nas reflexões acerca de outras experiências de trabalho pedagógico com a diferença na escola. Contudo, foi a abertura e/ou adoção de práticas escolares que priorizaram o respeito as diversidades e problematização da diferença, dentro da diferença. Asmemoriastrazidas pelosegundo autor deste texto, podem nos dar pistas sobre como a escola tem reconhecido que a diversidade e a diferença assumiram um papel importante no que diz respeito a educação no contexto multicultural e de reconheciemnto das diferenças.

Nas entrevistas testes realizadas no primiero momento do projeto "Rasgando uniformes e descosturando identidades de gênero no espaço escolar" mostraram parte da história dess@salun@s. Em seus discursos apareceram referencias continuas à cenas de homofobia durante as suas vidas escolares, muitas delas aconteceram nas salas de aula e provocadas por professores, que supostamente não sabem lidar ou não estavam preparados para lidar com as diferenças no espaço escolar. A exemplo quando um dos alunos fala sobrea sua sexualidade no Ensino Médio, mas fala disso entrecortando com memórias de sua vida escolar

... agora sim! Agora eu me sinto confortável e confiável. Há alguns anos atrás não, não me sentia... confortável. Porque eu sofria muito bullying, por conta do cabelo. Eu fui obrigado por força a agredir um colega de classe por conta do preconceito que era muito grande... Tenho o caso de uma professora de Educação Física. Um certo dia, em um dia de quinta-feira, e... o exercício seria futebol, eu não gosto de futebol! Também não sou obrigado! Ela, por vez me obrigou a jogar futebo na aula dela, eu disse que eu não iria jogar futebol na aula dela, e ela disse que enquanto eu tivesse na aula dela eu deveria jogar futebol sim, que na aula dela eu era homem, eu tinha que ser homem na aula dela... (ALUNO DA ESCOLA, 2016) ${ }^{15}$.

No trecho mencionado, fica claro sinais de desrespeito e de normatização, que é comum dentro de uma cultura heteronormativa, situações de conflito e de abusos aparecerem nas situações mais corriqueiras, diga-se de passagem nas mais particulares também, uma vez que no acontecimento mencionado, podemos observar como certos eventos poderia abrir espaços de baixo-estima e ou evasão escolar, e até de traumas. O aluno entrevistado demosntra desconforto em relação a revisitação das suas memórias, apesar de dizer que na atualidade estar mais confiante e mais confortável, há uma parte de sua 
subjetividade que está e poderá ficar marcada de forma negativa e desconfortável, suas mãos o tempo todo ficam inquietas e seus olhos demonstram . Ao afirmar que na época não gostava de futebol, houve um momento de plena convicção daquilo em que ele não se identifica , e confirma isso dizendo "eu não sou obrigado", uma fala que exprime empoderamente, que poderia ser traduzida assim: Eu não me obrigo, àquilo que os outros me obrigam! E se pudéssemos verificar toda a entrevista, verificaríamos outras falas em relação aos seus gostos, suas preferencias em relação ao esporte, bem como suas estratégias de permanencia na escola e nas aulas de educação física, discursos que serão analisados e apontaram mais resultados mais a frente na conclusão da pesquisa.

Muitas das entrevistas sinalizaram um certo conforto em relação à escola em que @s alun@s entrevistad@s estudam atualmente. @s oito alun@s entrevistad@s nas entrevistas pré testes, afirmaram que gostavam do Garcia porquelá el@s podem ser el@s mesm@s.Em seu dia-a-dia podem usar maquiagem, salto e unhas coloridas. Em muitas das atividades o colégio @s incluem com grande naturalidade.

Imagem 1: Estudantes e docente de Língua Inglesa
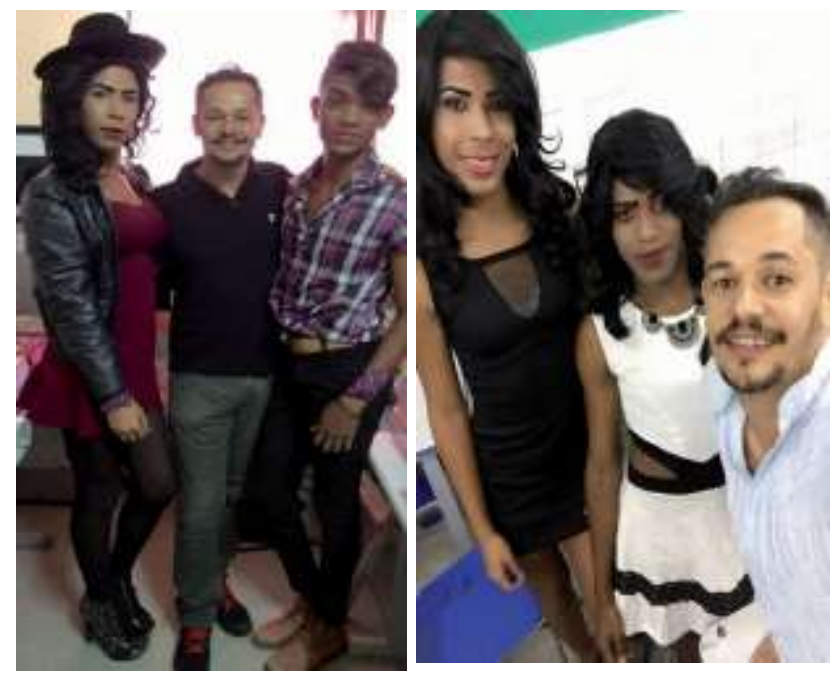

Fonte: Acervo próprio, 2017.

Apesar de referencias a momentos de homofobia, o que prevalece é a ideia de uma escola onde esses corpos podem ser protagonizados, onde corpos podem adiquirir maior visibilidade, as cenas/eventos escolares que foram escolhidos e mencionados neses texto, em diferentes tempos e diferenstes disciplinas escolares, são uma tentativa de dar um panorama sobre algumas ações pedagógicas da escola e de como as diferenças são negociadas no dia-a-dia . Acreditamos ser essa ainda uma história em desconstrução.

\section{O trabalho com a diversidade religiosa}

No ano de 2015 fora idealizado um projeto de produção de filmes, na verdade curtas, sobre a temática da Diversidade e de outros conteúdos escolares, como por exemplo gramática e outros assuntos mais formais do currículo escolar tradicional. O projeto fora batizado de Club GarFi, em alusão ao nome do próprio colégio. Um dos filmes mais vistos e comentados desse projeto foi A intolerância religiosa no ambiente escolar, segundo a descrição do projeto o intuito maior era comunicar e envolver a comunidade escolar - descrição postado junto com o próprio vídeo no canal youtube. Salienta-se que o texto, direção e produção do filme era de responsabilidade dos alunos envolvidos, no entanto participaram dele alun@s, professor@s e direção escolar, o que marca também o protagonismo dado pela escola aos alunos e alunas.

O filme é todo narrado a partir da ideia de respeito as diferenças religiosas, e apesar do tema central ser a intolerância religiosa no ambiente escolar, suas ideias e valores representam muito da crença do modelo pedagógico adotado pela escola e por intenções de uma pedagogia de valorização do sujeito, de sua trajetória e de suas crenças, elementos comuns a pedagogia queer.

Fazer um filme com a temática da religiosidade e de como algumas religiões e religiosos sofrem preconceito dentro da escola em relação as suas manifestações de crença, serve para ilustrar como a escola trata e educa @s alun@s a partir da concepção do “currículo como narrativa étnica racial" (SILVA, 2013). Levemos em consideração que a maior parte das cenas do curta são protagonizadas por um aluno praticante do Candomblé, isso serve para aproximar e desmistificar preconceitos em relação as religiões de matrizes africanas, bem como marcar os posicionamentos pedagógicos que 
comungam com as intenções do colégio. As marcas de um currículo como narrativa étnico racial, servem de suporte para abarcar outras questões como feminismo, igualdade de gênero, bullying no ambiente escolar, entre outras coisas.

\section{Produção de vídeo "A mulher que vendeu o marido por RS 1,99"}

Aqui segue a descrição e análise de um outro exemplo de como as práticas escolares dão voz a sujeitos silenciados, a questão central do vídeo descrito, diz respeito a igualdade de gênero e as questões centrais do feminismo, como por exemplo o empoderamento feminino. O vídeo foi publicado na rede mundial youtube e visualizado até o momento por 1.438 pessoas, ele serve de exemplo de como a escola pode colocar seu pensamento e suas inovações pedagógicas para além da escola.

O texto aborda a vida de uma mulher que é explorada por um marido alcoólatra, personagens comuns nas famílias e nas vidas de muitos dos alunos e alunas dessa escola. Certo dia, essa mulher resolve vender o seu marido por uma pequena quantia de dinheiro - no processo de venda e de desenvolvimento da narrativa-conto é possível perceber como outras questões sociais são problematizadas, tais como alcoolismo, fome e pobreza extrema, marcas sociais presentes em boa parte da comunidade onde a escola está localizada - o que isso nos mostra é a intenção e o comprometimento dessa escola com questões que a escola abraça em seu currículo transformador que não deixa de fora cenas e vivencias deseus/suas própri@sdiscentes.

\section{O Projeto We love dancing}

Entre os anos de 2008 e 2010 foram realizadas três versões do projeto We love dancing !, que objetivou promover apresentações de grupos de danças de rua, mais especificamente o Street Dance, tendo a sua primeira versão contado com 14 grupos e sua última com mais de 40 grupos compostos por alun@s de todos anos de ensino fundamental e médio da instituição.
O projeto We love dancing! começou a ser pensado no início do ano letivo de 2008, quando foi feita toda a escoIha dos conteúdos a serem trabalhados durante o ano, a partir da preocupação do corpo docente do Ensino Médio de como trabalhar o conteúdo oficial do vestibular e ao mesmo tempo associar com outras práticas? Para tanto, foi realizada uma seleção de textos que juntos formavam o eixo temático "Arte e qualidade de vida": Live a healthier life; live longer; The Beatles; The Peacock and The Crow; The Sicmillion megawatt smile ${ }^{16}$.

Após a escolha textual, o conteúdo gramatical e as inferências textuais foram ministrados em cada um dos bimestres que antecederam o último. Os textos foram trabalhados de diversas formas: aulas expositivas, jogos sobre cinema, escrita em inglês de receitas saudáveis, músicas e reescrita de fábula entre outras.

@s alun@s assistiram ao filme Aeon Flux e produziram relatórios sobre o filme Honey, no ritmo dos seus sonhos. Depois foram realizadas rodas de bate-papo para que @s alun@s pudessem expor seus pontos de vista sobre a história da personagem Honey Daniels, tomada neste trabalho como exemplo para atitudes altruístas em relação à vida. Além dos dois filmes foram sugeridos outros dois títulos para que@s alun@s assistissem em seus lares: Vem dançar e Se ela dança eu danço, todos os títulos sugeridos apresentam semelhanças temáticas.

Posteriormente, as turmas foram divididas em grupos para que pudessem criar coreografias em cima de músicas pop americanas, sendo desaconselhado pelo professor, textos que estimulassem o sexo inseguro, à violência, drogas e especialmente a vulgarização da mulher, comum em vídeos passados pela mídia. A conclusão sobre a adequação do texto deu-se após trabalho de tradução e observação de vocábulos, a partir daí os grupos transpuseram suas leituras para a linguagem corporal exigida na dança.

Os grupos se apresentavam para a comunidade escolar e para outras pessoas interessadas na apreciação do trabalho da escola. Além dos grupos escolares estiveram em algumas dessas apresentações outros grupos, com- 
postos por alun@s de uma escola municipal que atendia alun@s em vulnerabilidade social,grupo de idos@s, e um grupo de alun@s de outro município.

A diversidade de tipos de danças e necessidade de trabalho em equipe durante os meses que antecediam a culminância do projeto, propiciava aos/às alun@s interação e aproximação entre @s mesm@s, uma vez que estes passavam muito tempo junt@s, inclusive nos fins de semana ensaiando as suas coreografias, o que se percebeu é que houve uma grande mobilização de estudantes gays e lésbicas liderarem a coordenação dos trabalhos.

Além das questões de gênero, evidencia-se também o respeito aos corpos, em algumas apresentações de réplica de artistas midiáticos, o padrão de beleza imposto pela mídia foi quebrado, era possível ver Beyoncé bem acima do peso, cenas de travestismos - inclusive autorizadas pelos pais - e de apresentação de grupos de danças marginalizadas como o hip hop, ritmos ligados historicamente à cultura negra, mas que no palco da escola adquiriu diferentes cores e possibilidades pedagógicas.

Faz-se necessário desenvolver uma análise cuidadosa dos artefatos culturais, optamos por analisar apenas os depoimentos e memorias de um dos autores e as imagens de algumas das apresentações d@s estudantes, buscando enunciados "visíveis" (FOUCAULT, 2016). Assim, consideramos importante a utilização de imagens, visto que elas são um "texto discursivo e enunciativo, visível, que também conta a nossa história contemporânea" (SCHWENGBER, 2014, p. 265). Assim, as imagens

Imagem 2: Apresentações de dança de estudantes
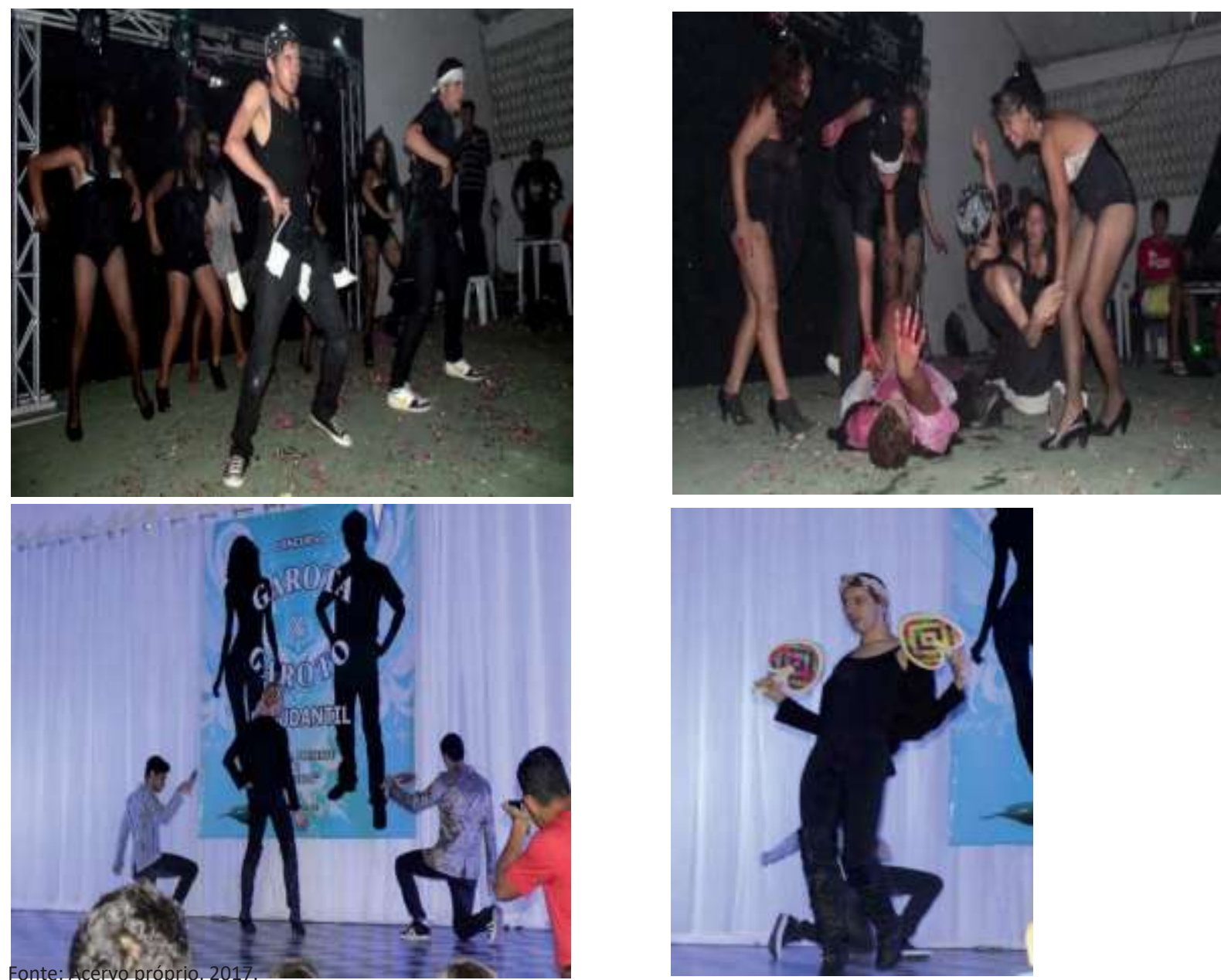
contribuem para nossa análise sobre as estratégias didáticas de temáticas da diversidade e da diferença, bem como uma postura queer no currículo.

Segundo Schwengber (2014, p. 264-265) as imagens "produzem e veiculam, em suas formas plásticas, concepções estéticas, políticas e sociais". Tomamos as imagens como um enunciado discursivo que desconstroe normas na contemporaneidade, a partir dos significados da tentativa de leitura através da fluidez da linguagem, bem como através do estabelecimento dos significados e da racionalização (SILVA, 2013). Assim, a instituição ao utilizar enunciados visíveis ligados ao exercício da desconstrução de uma linguagem, vinculada a uma rede discursiva que tenta determinar no decorrer dos anos, a cultura, modelos de comportamento, perfis, práticas estéticas e estímulos ao desejo heteronormativo, propoem desaprendizagens e a construção de um conheciemnto ressignificado.

As imagens destacadas aqui produzem saberes e aprendizagens que estimulam o enfrentamento ao discurso da heteronormatividade, principalmente quando tratamos de gênero e sexualidade naescola.

Então podemos considerar essas práticas como inovadoras no que se refere ao trabalho pedagógico com a diferença? Existem indícios de currículo queer? Apesar das cenas não nos permitir uma análise profunda desse currículo, elas nos possibilita refletir sobre práticas pedagógicas inovadoras, que estimulem a reflexões acerca dos limites e desafios que as discussões de gênero, diversidade sexual, relações étnicas, classe, geração, religião representam na escola, ao campo educação e a sociedade.

Ao desfazer o gênero e a sexualidade, combater o racismo e intolerância religiosa, a escola está, estranhando o currículo como é posto e demancando possibilidades de negociação no espaço escolar, na medida em que a performatividade do corpo pode ser negociada na interação. Nas palavras de Louro $(2015,49-50)$, uma pedagogia e um currículo queer:

Estariam voltados para o processo de produção das diferenças e trabalhariam, centralmente, com a intabilidade e a precariedade de todas as identidades. Ao colocarem em discussão as formas como o "outro" é construído, levariam a questionar as estreitas relações do eu com o outro. A diferença deixaria de estar lá fora, do outro lado, alheia ao sujeito, e seria compreendida como indispensável para a existência do próprio sujeito: ela estaria dentro, interagindo e constituindo o eu.

Acreditamos que uma pedagogia queer trabalharia com todos os corpos, identidades e subjetividades. Teria o poder de perturbar, desestabilizar, de propor desconstruções e desaprendizagens. A docência pode se transformar, e experiências didáticas como essas propõem desconstruções nas nossas concepções sobre por que, como e para que ensinar. A partir da experiência queer, afirmamos a importância da prática pedagógica dialógica, para trazer para a sala de aula e para a produção do conhecimento todas as vozes, sem invisibilizadar e/ou não reconhecer-las nesse campo.

Como argumenta Pinar (1998), uma pedagogia queer "desloca" e"descentra". Não precisamos reconhecê-la, mais sim, deixar escapar, deslocar, descentrar. Não precisamos de novos enquadramentos, mas sim, de novas posturas. Acreditamos que um bom início seria "estranhar" o currículo da escola. Essa pode ser uma das inovações que a pedagogia queer propõe ao currículo escolarhoje.

\section{Notas}

1 Ao longo do texto, optamos por utilizar a grafia “@” em lugar dos artigos o/a, que tentem a definir e universalizar o masculino (caso da linguagem sexista), ou, ainda, a dicotomizar masculino e feminino, fixando o gênero nessas duas vertentes, desconsiderando outras possibilidades de ser e estar.

2 "[...]Multiculturalismo, pós-estruturalismo, estudos de gênero, pós-modernismo, pós-colonialismo, pós-gênero, pós-feminismo, estudos culturais, estudos étnicos e raciais, pensamento da diferença e estudos queer" [...] (PARAÍsO, 2012, p. 23)

3 "O masculino vale mais que o feminino. Coisas feitas por homem têm mais valor do que coisas feitas por mulher" (CARVALHO; ANDRADE; MENEZES, 2009, p. 18).

4 "Refere-se ao posicionamento do homem e do ponto de vista masculino no centro da cultura e da história; normas e valo- 
res masculinos adquirem, assim, universalidade, com a consequente marginalização ou exclusão de experiências e valores femininos" (CARVALHO, et al., 2016, p. 10).

5 "Significa discriminação de sexo; historicamente, inferiorização das mulheres e consequente detenção de poderes e privilégios pelos homens"(CARVALHO, et al., 2016, p. 10).

6 Preconceito e discriminação social baseadas nas diferenças biológicas (cor da pele).

7 "É um sistema ideológico que assume a heterossexualidade como norma, com consequente homofobia, isto é, hostilidade e discriminação contra pessoas de orientação homossexual" (CARVALHO, et al., 2016, p. 10).

8 Os estudos queer sugiram como um "impulso crítico em relação à ordem sexual contemporânea, possivelmente associado à contracultura e às demandas daqueles que, na década de 1960 , eram chamados de novos movimentos sociais" (MISKOL$\mathrm{Cl}, 2013$, p. 21), tais como o movimento feminista, negro e homossexual.

9 "Queer es una crítica a las prácticas de normalización que se dan en el estudio de la sexualidad. [...] Queer alude a un conjunto de saberes (más que a un corpus teórico sistematizado y acabado) y a una disposición política".

10 "Queer hay que entenderlo como un adjetivo y como movimiento, acción, como un verbo: queerizar la escuela, la clase, el conocimiento, las metodologías (y los movimientos sociales, el espacio público y un largo etcétera). Una pedagogía queer, como apunta Luhman (1998) debería ir más allá de la incorporación del contenido queer en los currícula y de la preocupación sobre la búsqueda de estrategias de enseñanza que hagan ese contenido más accesible para el alumnado; y escribo esto sin dejar de pensar que muchas veces resulta inevitable moverse entre la urgencia de la práctica cotidiana (¿pero cómo llevamos todo esto al aula?) y el análisis y la reflexión".

11 Para Foucault (2015), o biopoder é exercido na carne, no biológico, no corporal, por meio de mecanismos disciplinares.

12 Colégio Estadual Dr. Antônio Garcia Filho, situado na cidade de Umbaúba, região centro-sul do estado de Sergipe. Ao longo de um pouco mais de meio século de existência, vem recebendo divers@s alun@s de diferentes com experiências escolares de outras como de escolas municipais situadas na cidade, de diversas comunidades rurais do município, além outras cidades circunvizinhas. O Colégio tem se destacado também nas avaliações nacionais, sendo considerado um dos melhores da Região Centro-sul do estado a partir de políticas estaduais de acompanhamento escolar.

13 Este depoimento foi extraído da pesquisa em andamento"Rasgando uniformes e descosturando identidades de gênero no espaço escolar" do PPGED/UFS. Informando que o segundo autor possui autorização de uso dos depoimentos e imagens utilizadas nesse texto, respeitando o acordo ético entre pesquisador e participantes.

14 Descrição realizada do professor da disciplina de língua estrangeira.

\section{Referências}

BENTO, B. Na escola se aprende que a diferença faz diferença. Estudos Feministas, v.19, n.2, pp. 549-559, mai-ago, 2011

CARVALHO, M.E.P.; ANDRADE, F. C. B.; MENEZES, C. S. Equidade de gênero e diversidade sexual na escola: por uma prática pedagógica inclusiva. João Pessoa: EDUFPB, 2009.

CARVALHO, M.E.P, et al. Direitos humanos das mulheres e das pessoas LGBTQI: inclusão da perspectiva da diversidade sexual e de gênero na educação e na formação docente. João Pessoa: EDUFPB, 2016.

DIAS, A. F. Como as escolas educam corpos nas práticas pedagógicas?. Revista Tempos e Espaços em Educação, v. 7, p. 103-112, 2014.

DIAS, A. F.; CRUZ, M. H. S. A produção/reprodução do corpo generificado na escola. Cadernos de Pesquisa, v. 22, p. 25, 2015.

DIAS, A. F. et al. Representações sobre corpo, gênero e sexualidades ao longo da vida: discursos de estudantes de Pós-graduação em Educação. Revista Cocar, v. 9, n. 17, p. 135-145, jan./ jul. 2015.

DIAS, A. F.; CARDOSO, H. M. . Subversões de Gênero nas Instituições Formativas. Cadernos de Educação, Tecnologia e Sociedade, v. 9, p. 351-358, 2016.

DIAS, A. F.; CARVALHO, M. E. P. ; OLIVEIRA, D. A. . Notas sobre o processo de inclusão/exclusão de uma professora transexual. Revista FAEEBA, v. 25, p. 145-158, 2016

DIAS, A. F. et al. Schooling and subversions of gender. Revista Tempos e Espaços em Educação, v. 10, n. 21, p. 83-92, 2017.

FOUCAULT, M. Microfísica do poder. Rio de Janeiro: Graal, 2015.

FOUCAULT, M. Arqueologia do Saber. 8a ed. Rio de Janeiro: Forense Universitária, 2016.

GASTALDO, D. Pesquisador/a descontruído/a e influente? Desafios da articulação teoria-metodoligia nos estudos pós-críticos. In: MEYER, D.E.; PARAÍSO, M.A. (orgs.). Metodologias de Pesquisas Pós-críticas em Educação. Belo Horizonte: Mazza Edições, 2012. 
LARROSA, J. J. Notas sobre a experiência e o saber de experiência. Revista Brasileira de Educação, n. 19, p. 20-28, jan./abr. 2002.

LOURO, G. L. Um corpo estranho: ensaios sobre sexualidade e teoria queer. 2aㅡ. ed. Belo Horizonte: Autêntica, 2015.

LUCENA, S.; OLIVEIRA, J. M. A. Culturas digitais na educação do Século XXI. Revista Tempos e Espaços em Educação, v. 7, n. 14, p. 35-44, 30 dez. 2014.

MAKNAMARA, M. Narrativas (auto)biográficas e necessidades formativas de futuros docentes de ciências: reflexões preliminares para um objeto em construção. Revista Tempos e Espaços em Educação, v. 8, n. 16, p. 99-108, 2015.

MISKOLCl, R. Teoria Queer: um aprendizado pelas diferenças. 2a ed. Belo Horizonte: Autêntica; EDUFOP, 2013.

NASCIMENTO, L. F.; CAVALCANTE, M. M. D. Abordagem quantitativa na pesquisa em educação: investigações no cotidiano escolar. Revista Tempos e Espaços em Educação, v. 11, n. 25, p. 249-260, 2018.

OLIVEIRA, J. B. G. A perspectiva da inclusão escolar da pessoa com deficiência no brasil: um estudo sobre as políticas públicas. Revista Tempos e Espaços em Educação, v.4, n.6, 2011.

PARASKEVA, J. M. "Brutti, Sporchi \& Cattivi": Towards a NonAbyssal Curriculum. Revista Tempos e Espaços em Educação, v. 9, n. 18, p. 75-90, 10 abr. 2016.

PEDRO, N. Ambientes educativos inovadores: o estudo do fator espaço nas 'salas de aula do futuro' portuguesas. Revista Tempos e Espaços em Educação, v. 10, n. 23, p. 99-108, 2017.

PEREIRA, A. A educação de jovens e adultos no sistema prisional brasileiro: o que dizem os planos estaduais de educação em prisões?. Revista Tempos e Espaços em Educação, v. 11, n. 24, p. 245-252, 2018.

PINAR, W. Introduction. In: PINAR, W. (org.). Queer Theory in Education. New Jersey e Londres: Lawrence Erlabaum Associates Publishers, 1998.

PINTO, É. J. S.; CARVALHO, M. E. P. DE; RABAY, G. as relações de gênero nas escolhas de cursos superiores. Revista Tempos e Espaços em Educação, v. 10, n. 22, p. 47-58, 2017.

SARAT, M.; CAMPOS, M. I. Gênero, sexualidade e infância: (con)formando meninas. Revista Tempos e Espaços em Educação, São Cristóvão, v. 7, n. 14, p. 45-56, 2014.

SCHWENGBER, M. S. V. O uso das imagens como recurso metodológico. In: MEYER, D. E.; PARAISO, M. A. Metodologias de pesquisas pós-críticas em educação. Belo Horizonte: Mazza Edições, 2012. 
SILVA, T. D. Documentos de Identidade: uma introdução às teorias do currículo. Belo Horizonte: Autêntica, 2013.

SOUSA, J. M. Currículo-como-vida. In PARAÍSO, M. A.; VILELA, R. A.; SALES, S. R. (Orgs.). Desafios contemporâneos sobre currículo e escola básica. Curitiba: Editora CRV, 2012.

TRUJILLO, G. Pensar desde otro lugar, pensar lo impensable: hacia una pedagogía queer. Educ. Pesqui., São Paulo, v. 41, n. especial, p. 1527-1540, dez., 2015.

Recebido em 05 de agosto de 2017.

Aceito em 01 de setembro de 2017. 